Jurnal Sistem Informasi (Journal of Information Systems). 1/12 (2016), 50-55

DOI: http://dx.doi.org/10.21609/jsi.v12i1.467

\title{
ANALISIS DAN PERANCANGAN TATA KELOLA TI MENGGUNAKAN COBIT 4.1 DOMAIN DELIVER AND SUPPORT (DS) PT XYZ
}

\author{
Inayatul Maghfiroh ${ }^{1}$, Murahartawaty ${ }^{2}$, dan Rahmat Mulyana ${ }^{2}$ \\ ${ }^{1}$ Information System, Industrial Engineering, Telkom University, Telekomunikasi Street Number 1, \\ Bandung, 40257, Indonesia \\ ${ }^{2}$ Telkom University, Telekomunikasi Street Number 1, Bandung, 40257, Indonesia
}

Email: 1inayatul.maghfiroh@gmail.com, ${ }^{2}$ murahartawaty@gmail.com, ${ }^{2}$ rahmat.moelyana@gmail.com

\begin{abstract}
IT Governance complements the implementation of IT in order to contribute the business value and reducing IT risks. IT Governance is a working basis to measure the use and utilization of IT to see the company's business goals and objectives. This study uses COBIT (Control Objectives for Information and Related Technology) in analysis and design. The first stage in this research is assessing maturity level to determine the level of IT maturity in PT XYZ Domain Deliver and Support (DS). Then the next stage is do priority analysis by mapping the company's goals with business goals, IT goals and IT process on COBIT 4.1. The next stage of the process resulting from the priority analysis is the analysis of current conditions which include gap analysis and risk analysis. Results of the research showed the critical processes that must be done for designing are DS1, DS4, DS6 and DS13 processes. The design is in the form of policies and procedures on critical processes.
\end{abstract}

Keyword: IT Governance, COBIT 4.1 maturity level, deliver and support, DS1

\begin{abstract}
Abstrak
Tata Kelola TI melengkapi keberadaan TI itu sendiri dengan tujuan agar implementasi TI dapat memberikan kontribusi nilai bagi bisnis dan mengurangi risiko TI. Tata Kelola TI merupakan sebuah landasan kerja yang dapat mengukur bagaimana penggunaan dan pemanfaatan TI dengan melihat bagaimana tujuan dan sasaran bisnis perusahaan. Penelitian ini menggunakan COBIT (Control Objective for Information and Related Technology) dalam melakukan analisis dan perancangannya. Tahap pertama pada penelitian ini yaitu dengan melakukan assessment maturity level untuk mengetahui tingkat kematangan TI PT XYZ Domain Deliver and Support (DS). Kemudian dilakukan analisis prioritas dengan memetakan sasaran perusahaan dengan business goals, IT goals, dan IT Process pada COBIT 4.1. Proses yang dihasilkan dari analisis prioritas kemudian dilakukan analisis kondisi saat ini yang mencangkup analisis gap dan analisis risiko. Hasil dari penelitian memperlihatkan bahwa proses kritikal yang harus dilakukan perancangan yaitu proses DS1, DS4, DS6 dan DS13. Perancangan yang dihasilkan berupa kebijakan dan prosedur atas proses-proses yang kritikal.
\end{abstract}

Kata Kunci: tata kelola TI, COBIT 4.1, tingkat kematangan, deliver and support, DS1

\section{Pendahuluan}

Teknologi Informasi (TI) yang berkembang sangat cepat telah memasuki hampir semua bidang kehidupan, salah satunya dalam dunia bisnis. Penerapan TI dalam dunia bisnis diperlukan sebagai alat bantu dalam upaya memenangkan persaingan, sehingga TI menjadi bagian yang tidak bisa terpisahkan dari suatu organisasi atau perusahaan saat ini. Agar implementasi TI dapat memberikan kontribusi nilai bagi bisnis dan mengurangi risiko TI, diperlukan sebuah Tata Kelola TI (IT Governance) yang baik sebagai suatu struktur dan proses pengambilan keputusan TI di tingkat korporat. Tata Kelola TI didefinisikan sebagai tanggung jawab eksekutif dan dewan direktur, dan terdiri atas kepemim- pinan, struktur organisasi serta proses-proses yang memastikan TI perusahaan mendukung dan memperluas obyektif dan strategi organisasi [1]. Tatakelola TI merupakan suatu siklus yang didorong adanya keinginan atau nilai dari pemangku kepentingan (stakeholder) yang akan menjadi rumusan strategi TI bagi organisasi. Strategi TI ini kemudian diselaraskan dengan strategi bisnis dan strategi organisasi [2]. Tata Kelola TI merupakan salah satu pilar utama dari Tata Kelola Perusahaan (Good Corporate Governance) yang merupakan salah satu langkah penting bagi Badan Usaha Milik Negara (BUMN) untuk meningkatkan dan memaksimalkan nilai perusahaan (corporate value). Peranan Tata Kelola TI yang menjadi salah satu aspek penting dari Tata Kelola Perusahaan secara keselu- 


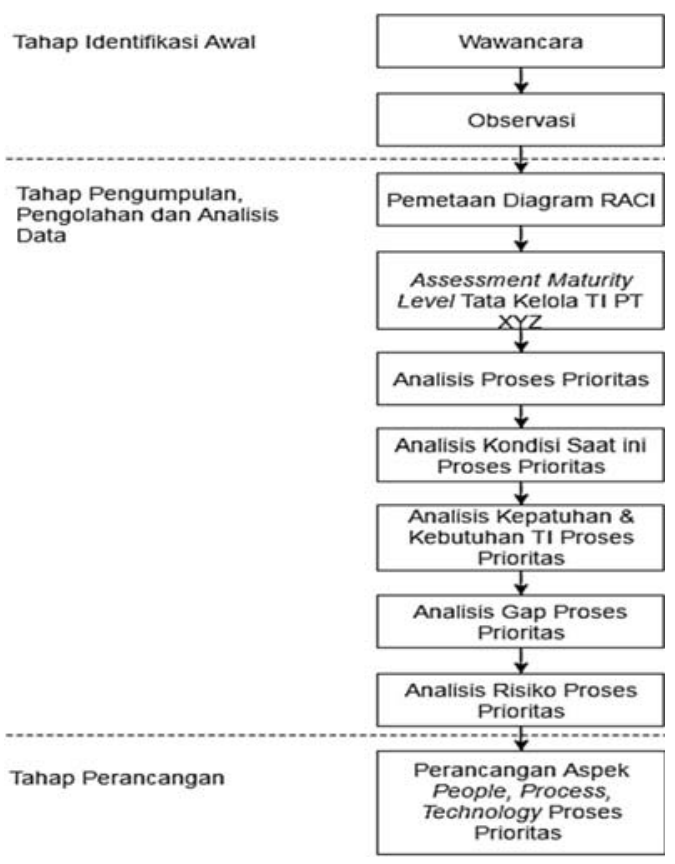

Gambar 1. Metodologi Penelitian

ruhan itulah diperlukan suatu pengukuran yang efektif dan efisien terhadap peningkatan bisnis perusahaan melalui struktur yang mengkolaborasikan proses-proses TI, sumber daya TI, dan informasi ke arah dan tujuan perusahaan [3].

PT XYZ merupakan salah satu perusahaan BUMN yang bergerak dalam bidang industri pengolahan vaksin dan anti sera. Kesadaran akan pentingnya GCG bagi BUMN tercantum dalam keputusan Peraturan Menteri Negara BUMN PER01/MBU/2011 [4]. Diperkuat dengan adanya Peraturan Menteri Negara BUMN PER-02/MBU/ 2013 Penyusunan Pengelolaan Teknologi Informasi [5], sehingga PT XYZ wajib mematuhi peraturan tersebut sebagai parameter untuk menjamin keselarasan TI dengan tujuan bisnis korporasi dan kebijakan strategis. Sub Bab Tujuan dan Sasaran pada PER-02/MBU/2013 menjelaskan bahwa terwujudnya pelaksanaan Tata Kelola TI yang baik dilakukan dengan menerapkan pola standarisasi kerangka pengelolaan TI pada setiap BUMN untuk dapat mendukung penerapan GCG secara komprehensif dengan salah satu sasarannya yaitu target maturity level dari Tata Kelola TI BUMN dalam 5 tahun ke depan adalah minimal maturity level 3. Sebagaimana tercantum dalam PER-02/ MBU/2013, terdapat framework yang dapat dijadikan referensi dalam menyusun Kebijakan TI BUMN untuk Tata Kelola TI diantaranya dapat dilakukan pendekatan dengan menggunakan framework COBIT, ISO 27001, ITIL, TOGAF dan PMBOK dengan beberapa penyesuaian yang diperlukan. Tidak dijelaskan seca-

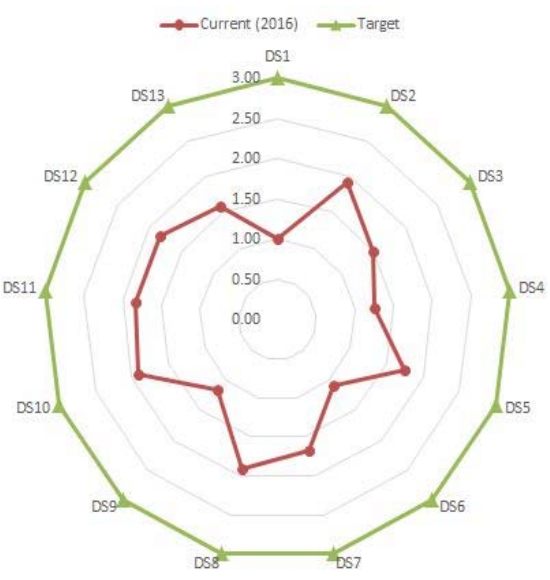

Gambar 2. Representasi Spider Chart

ra eksplisit untuk versi COBIT yang ada pada PER02/MBU/2013 tetapi cakupan proses yang dijelaskan didalamnya meliputi proses yang ada pada $\mathrm{CO}$ BIT 4.1. Berlandaskan peraturan menteri tersebut, maka penelitian ini menggunakan framework $\mathrm{CO}$ BIT 4.1.

\section{Metode}

Metodologi penelitian dapat dilihat pada Gambar 1 dengan rincian sebagai berikut.

\section{Tahap Identifikasi Awal}

Tahap identifikasi awal mencangkup wawancara awal dengan Kepala Divisi Teknologi Informasi terkait isu-isu yang ada yang berkaitan dengan proses-proses pada COBIT 4.1 untuk menentukan fokus domain yang akan diteliti sehingga penelitian tidak hanya pada unsur kebutuhan peneliti tetapi juga melibatkan kebutuhan dari sisi perusahaan. Setelah identifikasi awal, kemudian dilakukan observasi untuk memastikan kebenaran isu-isu yang dipaparkan sebelumnya. Kesimpulan yang didapat pada tahap ini bahwa isu-isu yang ada lebih banyak domain Deliver and Support (DS), dibandingkan domain Plan and Organise (PO), Acquire and Implement (AI), dan Monitor Evaluate (ME) pada framework COBIT 4.1.

\section{Tahap Pengumpulan, Pengolahan dan Analisa Data}

Langkah pertama dalam tahap pengumpulan, pengolahan dan analisa data yaitu pemetaan Diagram RACI setiap proses pada domain DS. Process activities and RACI charts (aktivitas-aktivitas proses dan Diagram RACI) menunjukkan jarak peranan umum dari responsible (tanggung jawab), account- 
TABEL 2

ASSESSMENT MATURITY DS

\begin{tabular}{lll}
\multicolumn{3}{c}{ ASSESSMENT MATURITY DS } \\
\hline \multirow{1}{*}{ Proses } & \multicolumn{2}{c}{$\begin{array}{c}\text { Tingkat } \\
\text { Kematangan }\end{array}$} \\
\cline { 2 - 3 } & \multicolumn{1}{c}{ As-is } & To-be \\
\hline DS1 Define and manage service levels & 1 & 3 \\
DS2 Manage third-party services & 1.92 & 3 \\
DS3 Manage performance and capacity & 1.5 & 3 \\
DS4 Ensure continuous service & 1.25 & 3 \\
DS5 Ensure systems security & 1.75 & 3 \\
DS6 Identify and allocate costs & 1.08 & 3 \\
DS7 Educate and train users & 1.67 & 3 \\
DS8 Manage service desk and incidents & 1.92 & 3 \\
DS9 Manage the configuration & 1.17 & 3 \\
DS10 Manage problems & 1.92 & 3 \\
DS11 Manage data & 1.83 & 3 \\
DS12Manage the physical environment & 1.83 & 3 \\
DS13 Manage operations & 1.58 & 3 \\
Rata-rata Domain DS & 1.57 & 3 \\
\hline
\end{tabular}

able (akuntabel), consulted (dikonsultasikan), dan informed (diinformasikan) untuk kegiatan-kegiatan inti [6]. Pemetaan Diagram RACI akan berguna untuk Assessment Maturity Level sehingga dalam melakukan wawancara assessment dapat langsung menuju orang yang menanganinya. Selanjutnya pada proses pengolahan akan dilakukan analisis prioritas dengan cara memetakan sasaran perusahaan dengan business goals, IT goals, dan IT process COBIT 4.1. Setelah analisis prioritas kemudian akan dilakukan analisis Kepatuhan dan Kebutuhan TI yang mana kepatuhan TI berbicara mengenai kewajiban dari PT XYZ untuk memenuhi PER-01/ MBU/2011 dan PER-02/MBU/2013 untuk mencapai tingkat kematangan rata-rata minimal 3 pada tahun 2018. Sedangkan kebutuhan TI berbicara mengenai amanat dari RJPP (Rencana Jangka Panjang Perusahaan) mengenai kebutuhan dukungan TI ke depan untuk mendukung pencapaian tujuan bisnis PT XYZ. Hasil analisis tersebut akan dilakukan analisis gap dan analisis risiko yang menggambarkan dampak yang mungkin didapatkan PT XYZ jika gap ini tidak ditindaklanjuti.

\section{Tahap Perancangan}

Tahap perancangan akan meliputi tiga aspek yaitu People, Process, and Technology sesuai dengan prioritas yang didapatkan sehingga dapat memberikan nilai tambah bagi perusahaan itu sendiri. Perancangan yang sudah dibuat kemudian akan diverifikasi dan divalidasi oleh pihak perusahaan sehingga apabila dalam perancangan terdapat kekurangan, maka akan dilakukan perbaikan dan dilakukan verifikasi dan validasi ulang.

\section{Hasil dan Analisis}

Hasil yang diperoleh dapat dirinci sebagai berikut:
TABEL 1

KonVERSi Nilai Business GoALS

\begin{tabular}{cccc}
\multicolumn{4}{c}{ KONVERSI NILAI BUSINESS GOALS } \\
\hline $\begin{array}{c}\text { Perspektif } \\
\text { Kinerja }\end{array}$ & $\begin{array}{c}\text { Business } \\
\text { Goals }\end{array}$ & Skor & $\begin{array}{c}\text { Rata-rata skor } \\
\text { per perspektif }\end{array}$ \\
\hline Financial & BG1 & 8.5 & 6.1 \\
& BG2 & 4.9 & \\
& BG3 & 4.9 & \\
\hline Customer & BG4 & 7.9 & 7.8 \\
& BG5 & 7.7 & \\
& BG6 & 8.7 & \\
& BG7 & 3.3 & \\
& BG8 & 9.7 & \\
& BG9 & 9.2 & \\
\hline Internal & BG10 & 10.0 & 7.4 \\
& BG11 & 3.8 & \\
& BG12 & 7.4 & \\
& BG13 & 8.5 & \\
& BG14 & 4.4 & \\
\hline Learning and & BG15 & 10.0 & \\
Growth & BG16 & 9.2 & 5.1 \\
\hline
\end{tabular}

\section{Assessment Maturity Level}

Assessment Maturity Level dilakukan setelah melakukan pemetaan Diagram RACI disusul dengan melakukan wawancara assessment dengan beberapa narasumber pada PT XYZ. Assessment Maturity Level dilakukan dengan menggunakan 6 maturity attribute yaitu Kebijakan, Perencanaan dan Prosedur (Policies, Plans, and Procedures); Tanggung Jawab dan Akuntabilitas (Responsibility and Accountability); Penetapan dan Pengukuran Tujuan (Goal Setting and Measurement); Keterampilan dan Keahlian (Skill and Expertise); Kesadaran dan Komunikasi (Awereness \& Communication); Alat dan Otomatisasi (Tools and Automation). Tabel 1 akan memperlihatkan hasil dari assessment maturity level. Hasil dari maturity level DS dapat dipresentasikan dengan spyder chart pada Gambar 2.

Berdasarkan Tabel 1, dapat diketahui bahwa dengan rata-rata nilai maturity domain $\mathrm{DS}=1.57$ dan target $=3$, terdapat selisih sebesar 1.43 untuk mencapai target yang diharapkan. Hasil ini menunjukkan bahwa PT XYZ masih belum memiliki tata kelola TI yang baik dengan banyaknya temuan pada beberapa proses yang masih bersifat ad hoc.

\section{Analisis Proses Prioritas}

Analisis prioritas dilakukan dengan memetakan sasaran perusahan yang tercantum pada Rencana Jangka Panjang Perusahaan (RJPP) PT XYZ dengan Business Goals, IT Goals, dan IT Process berdasarkan COBIT 4.1. Tabel 2 menunjukkan hasil pemetaan sasaran perusahaan dengan Business Goals COBIT 4.1, sedangkan Tabel 3 menunjukkan hasil pemetaan sasaran perusahaan dengan IT Goals COBIT 4.1 dan Tabel 4 menunjukkan hasil pemeta- 
TABEL 3

\begin{tabular}{llll}
\multicolumn{4}{c}{ KONVERSI NILAI IT GOALS } \\
\hline \multicolumn{1}{c}{ IT Goals } & Skor & IT Goals & Skor \\
\hline ITG1 & 3.8 & ITG15 & 3.8 \\
ITG2 & 7.0 & ITG16 & 8.7 \\
ITG3 & 7.9 & ITG17 & 4.9 \\
ITG4 & 9.2 & ITG18 & 4.9 \\
ITG5 & 6.2 & ITG19 & 6.2 \\
ITG6 & 7.2 & ITG20 & 7.2 \\
ITG7 & 8.4 & ITG21 & 6.2 \\
ITG8 & 7.9 & ITG22 & 7.0 \\
ITG9 & 1.0 & ITG23 & 8.3 \\
ITG10 & 9.2 & ITG24 & 7.4 \\
ITG11 & 8.1 & ITG25 & 6.3 \\
ITG12 & 9.2 & ITG26 & 8.3 \\
ITG13 & 7.4 & ITG27 & 7.4 \\
ITG14 & 4.9 & ITG28 & 6.8 \\
\hline
\end{tabular}

an sasaran perusahaan dengan IT Process Domain DS COBIT 4.1.

Hasil dari pemetaan-pemetaan tersebut, kemudian dilakukan peringkat dari nilai tertinggi yang berarti sangat prioritas sampai nilai terendah yang berarti kurang prioritas. Keseluruhan hasil assessment dan analisis kemudian dikomunikasikan dengan pihak perusahaan. Komunikasi dilakukan dengan suatu kegiatan FGD (Focus Group Discussion) yang melibatkan manajerial TI PT XYZ. Hasil dari diskusi tersebut, tim manajerial TI setuju dengan hasil assessment dan analisis prioritas. Akan tetapi, untuk proses yang akan dilakukan perancangan pihak manajerial TI memberikan rekomendasi proses yang sesuai dengan kebutuhan PT XYZ saat ini. Proses yang direkomendasikan masih tergolong proses yang diprioritaskan untuk dilakukan perancangan, sehingga diskusi tersebut menghasilkan proses yang akan dilakukan perancangan di antaranya adalah DS1 Define and manage service levels; DS4 Ensure continuous service; DS6 Identify and allocate cost, dan DS13 Manage operation. Pada proses terpilih, kemudian dilakukan justifykasi guna memperkuat alasan terpilihnya proses prioritas. Justifikasi proses terpilih dijelaskan pada Tabel 5.

\section{Analisis Kondisi Saat Ini}

Analisis kondisi taat ini merupakan kondisi yang sedang terjadi di PT XYZ. Analisis kondisi saat ini didapat dari wawancara assessment maturity pada tahap sebelumnya. Penjelasan kondisi saat ini tercantum pada Tabel 6 .

\section{Analisis Kepatuhan dan Kebutuhan TI}

Analisis kepatuhan dan kebutuhan akan mencakup 6 Maturity Attribute yaitu Kebijakan, Perencanaan dan Prosedur (Policies, Plans, and Procedures); Tanggung Jawab dan Akuntabilitas (Responsibility and Accountability); Penetapan dan Pengukuran
TABEL 4

KONVERSI NILAI IT PROCESS

\begin{tabular}{lc}
\multicolumn{2}{c}{ KONVERSI NILAI IT PROCESS } \\
\hline \multicolumn{1}{c}{ Proses } & Skor \\
\hline DS1 Define and manage service levels & 7.0 \\
DS2 Manage third-party services & 8.8 \\
DS3 Manage performance and capacity & 5.3 \\
DS4 Ensure continuous service & 7.2 \\
DS5 Ensure systems security & 6.5 \\
DS6 Identify and allocate costs & 7.8 \\
DS7 Educate and train users & 6.4 \\
DS8 Manage service desk and incidents & 7.9 \\
DS9 Manage the configuration & 4.4 \\
DS10 Manage problems & 7.2 \\
DS11 Manage data & 7.6 \\
DS12Manage the physical environment & 6.0 \\
DS13 Manage operations & 7.5 \\
Rata-rata skor per domain & 6.9 \\
\hline
\end{tabular}

Tujuan (Goal Setting and Measurement); Keterampilan dan Keahlian (Skill and Expertise); Kesadaran dan Komunikasi (Awereness \& Communication); Alat dan Otomatisasi (Tools and Automation); yang kemudian akan dikelompokkan menjadi 3 aspek yaitu People, Process, dan Technology. Berikut adalah analisis 3 aspek pada proses yang menjadi prioritas yaitu DS1, DS4, DS6, dan DS13.

Pada poses prioritas secara keseluruhan, rekomendasi yang diberikan untuk aspek teknologi adalah dengan menggunakan aplikasi yang dapat membantu terlaksananya proses prioritas sehingga kinerja proses dapat dengan mudah diukur dan dimonitor.

\section{Analisis Gap dan Risiko}

Analisis Gap dilakukan berdasarkan perolehan nilai dari Assessment Maturity Level dan yang berfungsi untuk mengetahui seberapa besar kesenjangan yang terdapat pada masing-masing proses dan menjelaskan apa saja yang menyebabkan kesenjangan itu ada.

Analisis risiko dilakukan bersama saat analisis gap sehingga dari analisis gap tersebut dapat diketahui dampak dan probability dari masing-masing proses. Penentuan tingkat risiko mengacu pada tingkat risiko korporat yang ada dalam salah satu prosedur risiko PT XYZ.

\section{Rekomendasi}

Dari analisis gap dan risiko, kemudian disusun rekomendasi menuju nilai tingkat kematangan 3 (Define Process) untuk masing-masing proses sebagai berikut:

DS1 Define and manage service levels Membuat pedoman dan prosedur penyusunan Service Level Management antara penerima dan penyedia layanan, yang mencakup kebutuhan layanan, ketetapan layanan, SLA (service level agree- 
TABEL 5

JUSTIFIKASI PROSES TERPILIH

\begin{tabular}{|c|c|}
\hline Proses & Justifikasi \\
\hline $\begin{array}{l}\text { DS1 } \\
\text { Define and } \\
\text { manage } \\
\text { service levels }\end{array}$ & $\begin{array}{l}\text { Fokus utama proses DS1 yaitu mengidentifikasi persyaratan-persyaratan layanan, persetujuan terhadap mu- } \\
\text { tu layanan (SLA), dan memonitor pencapaian setiap mutu layanan. Fokus tersebut bertujuan agar pen- } \\
\text { capaian mutu layanan dapat diawasi dan dilaporkan secara terus menerus sehingga presentasi jumlah stake- } \\
\text { holder bisnis yang merasa puas akan penyampaian layanan sesuai dengan level atau mutu yang sudah dite- } \\
\text { tapkan sebelumnya. Proses DS1 juga harus bisa memastikan keselarasan layanan TI yang ada dengan strate- } \\
\text { gi bisnis perusahaan PT XYZ. }\end{array}$ \\
\hline $\begin{array}{l}\text { DS4 } \\
\text { Ensure } \\
\text { continuous } \\
\text { service }\end{array}$ & $\begin{array}{l}\text { Fokus utama proses DS4 yaitu menyediakan layanan TI berkesinambungan yang membutuhkan pengem- } \\
\text { bangan, pemeliharaan, dan pengujian perencanaan TI yang berkesinambungan pula sehingga proses laya- } \\
\text { nan yang secara efektif berkesinambungan akan meminimalkan kemungkinan dan dampak dari interupsi } \\
\text { layanan utama TI PT XYZ pada proses-proses dan fungsi-fungsi utama bisnis PT XYZ. }\end{array}$ \\
\hline $\begin{array}{l}\text { DS6 } \\
\text { Identify and } \\
\text { allocate cost }\end{array}$ & $\begin{array}{l}\text { Fokus utama proses DS6 yaitu memperlihatkan gambaran biaya TI yang lengkap dan akurat, sistem alokasi } \\
\text { biaya yang fair dan disetujui oleh business user, dan sistem pelaporan alokasi biaya dan pemakaian TI yang } \\
\text { tepat waktu. Proses DS6 bertujuan untuk memastikan transparasi dan pemahaman terkait biaya TI dapat } \\
\text { dimengerti oleh manajerial TI sehingga dapat meningkatkan efisiensi biaya terhadap layanan TI yang saat } \\
\text { ini digunakan oleh PT XYZ. }\end{array}$ \\
\hline $\begin{array}{l}\text { DS13 } \\
\text { Manage } \\
\text { Operation }\end{array}$ & $\begin{array}{l}\text { Fokus utama proses DS13 yaitu memenuhi kegiatan operasional setiap level layanan untuk penjadwalan } \\
\text { pemrosesan data, melindungi keluaran yang sensitif serta pengawasan dan pemeliharaan infrastruktur. } \\
\text { Proses DS13 bertujuan untuk menjaga integritas data dan memastikan bahwa infrastruktur TI PT XYZ } \\
\text { dapat menahan dan memulihkannya dari kesalahan dan kegagalan yang sewaktu-waktu dapat terjadi. }\end{array}$ \\
\hline
\end{tabular}

ments), OLA (operating level agreements), dan sumber daya terkait. Kemudian, mengawasi dan melaporkan pencapaian service level secara terus menerus, dan laporan diberikan dalam bentuk formal, membuat program survey kepuasan pelanggan atas pelayanan TI sehingga dapat menjadi tolok ukur dan dasar untuk perbaikan layanan TI. Lalu, meninjau SLA secara teratur untuk memastikan efektifitas, hal-hal terbaru, dan apabila ada perubahan maka harus disertai dengan penjelasan. Selain itu, menambah entitas struktur baru yakni Service Manager yang berfokus pada layanan TI yang kinerjanya dapat dilaporkan secara berkala, serta menggunakan tools terkait service level untuk memudahkan dalam monitoring dan reporting service level.

\section{DS4 Ensure continuous service}

Di antaranya adalah membuat pedoman dan prosedur penyusunan keberlangsungan layanan yang mencakup keberlangsungan TI, membuat dan memelihara perencanaan TI berdasarkan kerangka yang menjamin keberlangsungan layanan untuk mengurangi dampak gangguan utama pada proses dan fungsi bisnis utama, dan meninjau fungsi TI setelah bencana, dengan membuat prosedur-prosedur untuk menaksir kecukupan perencanaan dan pembaharuan perencanaan yang sesuai.

Termasuk juga menetapkan tindakan yang diambil pada waktu tertentu ketika TI sedang dalam perbaikan, dan layanan tetap harus tersedia, salah satunya dengan aktivasi backup, mengadakan pelatihan dalam implementasi DRP dengan sumber yang ahli, menambah entitas struktur yang dapat melaksanakan proses, serta membentuk DRT sehingga saat terjadinya bencana tidak ada keambiguitasan terkait tanggung jawab pemulihannya.
DS6 Identify and allocate cost

Yang termasuk dalam proses ini adalah membuat pedoman dan prosedur yang memadai terkait identifikasi, pengumpulan dan pengalokasian biaya TI, menentukan model akuntansi biaya sehingga dapat menentukan biaya operasional TI yang tepat dan dapat diterapkan dalam seluruh kasus atau kegiatan TI, mengadakan pelatihan terkait identifikasi biaya standar atas operasional TI untuk kebutuhan perhitungan alokasi, biaya layanan dan pengembalian investasi.

Penambahan entitas struktur yang berfokus pada akuntansi TI serta penggunaan tools yang sesuai juga diperlukan guna menunjang keberlangsungan proses ini.

\section{DS13Manage Operation}

Yang tergolong proses ini adalah menetapkan, menerapkan dan memelihara prosedur standar operasi TI dan memastikan tugas-tugas yang ada telah sesuai dengan SDM terkait. Selain itu, melakukan penambahan prosedur sesuai dengan kondisi TI saat ini agar lebih relevan dalam hal operasionalnya.

Pemenuhan sumber daya yang dibutuhkan oleh TI baik secara kuantitas maupun kualitas juga perlu dilakukan sehingga dapat mengoptimalkan kinerja TI dalam mencapai tujuan perusahaan. Penggunaan tools terkait dapat dilakukan agar tercipta automation untuk proses ini.

\section{Kesimpulan}

Pada penelitian ini, beberapa kesimpulan yang dapat diambil adalah bahwa erdasarkan assessment maturity level, proses Domain DS dengan nilai maturity 1.57 menjelaskan bahwa domain tersebut be- 
TABLE 6

Kebutuhan Dan KePatuhan AsPeK PROCESS

\begin{tabular}{cl}
\hline Proses & \multicolumn{1}{c}{ Rekomendasi Proses } \\
\hline DS1 & - Pedoman Service Level \\
& - Prosedur Baku Pengelolaan Service Level \\
& - Template Service Catalogue \\
& - Template Service Level Requirement \\
& - Template Service Level Agreement \\
& - Template Operational Level Agreement \\
& - Template Contract Review Report \\
& - Checklist Program Survei Kepuasan User \\
& atas Pelayanan TI \\
DS4 & - Porm Reporting SLA \\
& - Prosedur Baku IT Disaster Recovery Plan \\
& - Template IT Disaster Recovery Plan \\
DS6 & - Pedoman Alokasi Biaya TI \\
& - Prosedur Baku Identifikasi Alokasi Biaya \\
& TI \\
& - Tempalate IT Financial \\
DS13 & - Pedoman Operasi TI \\
& - Prosedur Baku Pengelolaan Operasi TI \\
\hline
\end{tabular}

rada pada level 1 yaitu initial/ad hoc, yang berarti PT Bio Farma telah menyadari kepentingan suatu proses untuk mendukung strategi TI itu sendiri maupun bisnis. Beberapa proses telah berjalan based on practice dengan inisiatif individu, sebagian sudah terdokumentasi dalam bentuk prosedur baku dan dokumen pendukung lain. Pelatihan formal secara terjadwal bagi unit TI maupun user belum dikelola dengan baik sehingga belum dapat meningkatkan kompetensi secara optimal. Untuk dapat mencapai maturity level yang diharapkan pada level 3 (define process) maka prosedur yang telah direkomendasikan harus terpenuhi. Oleh karenanya, pada penelitian ini akan menghasilkan perancangan tata kelola TI proses terkait.

Karena penelitian ini hanya merupakan saran bagi PT XYZ agar dapat meningkatkan tata kelola TI dengan proses yang terbatas, harapan untuk pe- nelitian selanjutnya adalah melakukan analisis untuk semua proses TI yang ada dalam COBIT 4.1 agar dapat meningkatkan tata kelola TI di PT XYZ secara terstruktur berdasarkan prioritasi proses.

\section{Referensi}

[1] G. Institute, COBIT® 4.1: Framework, Control Objectives, Management Guidelines, Maturity Models. USA: IT Governance Institute, 2007.

[2] H. Nugroho, "Usulan Tahapan Perbaikan Tata Kelola TI Pada PT XYZ Berdasarkan Hasil Penilaian COBIT 4.1 Maturity Model," SEMNASTEKMEDIA, Vol. 4.11, Pp. 97-101, 2016.

[3] E, Saputra, "Analisis Tata Kelola TI Dengan Menggunakan Metode Cobit 4.1 (Studi Kasus: BPR Danagung Bakti Yogyakarta)," Magister Teknik Informatika, Universitas Atma Jaya Yogyakarta, Yogyakarta, 2015

[4] Kepala Biro Hukum, "Peraturan Menteri Negara Badan Usaha Milik Negara Nomor: PER-01/MBU/2011 Tentang Penerapan Tata Kelola Perusahaan Yang Baik (Good Corporate Governance) Pada Badan Usaha Milik Negara.," Jakarta, 2011.

[5] Kepala Biro Hukum, "Peraturan Menteri Negara Badan Usaha Milik Negara Nomor: PER-02/MBU/2013 Tentang Panduan Penyusunan Pengelolaan Teknologi Informasi Badan Usaha Milik Negara.," Jakarta, 2013.

[6] G, Wirayudha, "Pengukuran Maturity Level Sistem Informasi Manajemen Pusat Informasi Komuditas Dinas Pertanian Provinsi Jawa Barat Dengan Menggunakan Kerangka Kerja COBIT 4.1," Magister Sistem Informasi, Universitas Komputer Indonesia, Bandung, 2014. 